Title:

\title{
United Nations General Assembly tuberculosis targets: are we on track?
}

The 2018 UN General Assembly (UNGA) Political Declaration on Tuberculosis was a turning point in global efforts to end the tuberculosis epidemic. ${ }^{1,2}$ Ambitious targets were set for scaleup and rollout of diagnostic, treatment, and prevention services, political commitments, principles of equity and human rights, and financing implementation and research. Targets included diagnosing and treating an additional 40 million people with tuberculosis by 2022 and generating US\$13 billion per year for tuberculosis care and prevention and US\$2 billion per year for research and development. Is progress in achieving these targets on track?

There has been some progress on action, accountability, and funding but it has been much slower than anticipated. For other targets, progress is not on track and challenges remain. Political commitment from the heads of state of some countries with a high burden of tuberculosis has been forthcoming. In 2019, the First Lady of Nigeria, Aisha Buhari, Tuberculosis Ambassador and Champion, convened tuberculosis stakeholder meetings and appointed the spouses of governors of all 36 Nigerian states as Tuberculosis Champions so that political leadership can be cascaded down from central government to state level for governance of tuberculosis control programs . The Prime Minister of India tripled the domestic tuberculosis budget in 2019 aiming to end tuberculosis earlier than the global Sustainable Development Goal target, and personally monitors progress. ${ }^{3}$ In December, 2019, the Indonesian President appointed the chair of the national tuberculosis partnership as adviser and made tuberculosis a priority. In November, 2019, The Pakistan Prime Minister mandated regular updates from the Ministry of Health. The President of Mozambique participated in the 2019 World TB Day event and the President of Philippines officiated the opening session of the 2019 TB Union's regional conference in Manila. In many high tuberculosis burden countries, political commitment is reflected in national tuberculosis strategic plans. However, these commitments need to be matched with substantial increases in domestic funding for scaling-up of TB services, careful monitoring of implementation of national strategies, and holding leaders accountable

The quality of care experienced by many patients with TB globally has been suboptimal due to human rights, gender-related and other barriers to accessing TB services (insert new ref: The Global Fund, February 2020, Geneva. Technical Brief Tuberculosis, Gender and Human Rights https://www.theglobalfund.org/media/6349/core_tbhumanrightsgenderequality_technicalbri 
ef_en.pdf -accessed 8th March 2020). We are beginning to see advances in achieving the targets for ending stigma and discrimination and transforming the tuberculosis response to be equitable, rights-based, and people-centred. A declaration of rights of people affected by tuberculosis was developed in 2019 by TB-People-a network of tuberculosis survivors and the Stop TB Partnership. ${ }^{4}$ It describes 22 different rights of people affected by TB, and the legal obligations and responsibilities of the state and non-state stakeholders under human rights law which need to implemented to improve seeking and uptake of TB testing and treatment services.

A series of assessment tools developed by the STOP TB Partnership (new ref: STOP TB Partnership: Communities, Human Rights and Gender http://www.stoptb.org/communities/ accessed $8^{\text {th }}$ March, 2020) are being taken forward in all high TB endemic countries. These will assist countries in transforming the TB response to be equitable, rights-based, gendertransformative and people-centered to protect, advance and advocate for gender equality and human rights-based health initiatives, change attitudes, combat stigma, improve levels of TB knowledge and rights, raise awareness about available TB services, promote social accountability to ensure universal access to TB care and support services and reach populations most at risk, vulnerable, underserved and affected by TB The WHO Gender Assessment Tool (GAT) which can assess the gender-responsiveness (gender-sensitive, specific or -transformative) of activities of the programme and identify areas where genderresponsiveness can be improved, are being used to take action on gender, stigma, and the legal environment. Mobile apps for monitoring tuberculosis services by communities are being piloted in selected countries, such as Cambodia, Indonesia, Mozambique, Tajikistan and Ukraine that might reach more people for monitoring in the coming years

Progress is being made towards achieving the 40 million tuberculosis treatment target (figure). For the first time ever, global tuberculosis treatment notification reached 7 million, 600 000 more treatment notifications than in $2017 . .^{5}$ Half of this global increase in notifications was from India and Indonesia, countries which rank first and third among the highest tuberculosis burden countries. However, an estimated 3 million people with active tuberculosis remain undiagnosed and untreated globally. Estimates for 2019 indicate that more than 1.2 million additional tuberculosis treatments will be notified in 2019 than in 2015.

Momentum must be accelerated for the other tuberculosis targets that are off track. Progress on diagnosing and treating patients with multidrug-resistant (MDR) tuberculosis has been slow. 
In 2018, 156200 people with MDR tuberculosis were diagnosed and treated globally, only 17 000 more than in 2017. Worryingly, over 300000 people with MDR tuberculosis were left undiagnosed and untreated. ${ }^{5}$ To meet the UNGA target for treating 1.5 million people with MDR tuberculosis by 2022, two major gaps need to be addressed: the drug sensitivity testing diagnostic gap and the successful treatment gap. WHO's revised guidelines on rapid molecular testing and on use of all oral MDR tuberculosis treatment regimens now provide hope for increasing treatment success rates. ${ }^{6,7}$

The target to treat 115000 children for MDR tuberculosis between 2018 and 2022 cannot be assessed. Although availability and rollout of new child friendly formulations ${ }^{8}$ for tuberculosis and MDR tuberculosis is increasing, WHO does not have data on numbers of children treated for MDR tuberculosis. Disaggregated data by age and sex are essential to ensure equity in access to treatment for MDR tuberculosis. Progress for the target of putting 30 million people on tuberculosis preventive therapy (TPT) during 2018-22 is not on track..$^{5}$ From 2019 onwards national HIV programmes have prioritised putting people living with HIV on TPT, but the technical and operational challenges of placing tuberculosis contacts on TPT has to be addressed to achieve targets set. Scale up of TPT for contacts needs to be grouped together with active tuberculosis case finding to address the operational challenges hindering progress. There is hope that targets that are not on track can still be achieved. In 2018, funding for research and development was increased to over US\$900 million, up from US\$700 million in previous years. The successful replenishment of the Global Fund to Fight AIDS, Tuberculosis and Malaria in 2019 has translated into increased allocations to the highest tuberculosis burden countries. To reach the targets in 2020-22, the Global Fund allocated additional catalytic funding for 20 high burden countries that account for more than $80 \%$ of the global undiagnosed tuberculosis burden. The Global Fund is the main external donor for tuberculosis and provides $18 \%$ of its resources to tuberculosis - an amount that needs to be increased substatially. ${ }^{9,10}$ Epidemiological modelling indicates that, each US dollar invested will get a return on investment of US\$44 for achieving the UNGA Political Declaration on Tuberculosis targets. Yet funding is inadequate; available funding for tuberculosis care and prevention is only half of what is needed while only a third of research and development needs are funded. Given this huge funding gap, it is crucial that increased funding for tuberculosis from traditional and nontraditional sources is obtained. ${ }^{9,10}$ The Global Plan for reaching the UN tuberculosis targets describes actions needed to increase resources for tuberculosis, including actions by 
governments of high TB burden countries, donors, development banks, health insurance stakeholders, private sector and innovative funding actors. ${ }^{10}$

A multisectoral accountability framework was developed by WHO in response to the UNGA Political Declaration on Tuberculosis that mandated review with provision of a progress report to the UN General Assemblies of 2020 and 2023. The need for independence of the accountability mechanism was emphasised by the Lancet Commission on tuberculosis. ${ }^{11}$. This accountability framework needs to be implemented with active engagement by, and representation of, independent stakeholders, including civil society, non-governmental organisations, civil society, and multilateral and bilateral organisations. Encouragingly, regional political platforms, such as the African Union, have started to discuss scorecards for accountability. The promises made by the UNGA Political Declaration on Tuberculosis are not enough. ${ }^{12}$ It is time all high-burden tuberculosis countries, with the active engagement of donors and all stakeholders, including local communities affected by tuberculosis, commit more to implementing this accountability framework if the tuberculosis targets are to be achieved in the stated timelines.

The theme for World TB Day on March 24, 2020, is appropriately designated "It's Time". Deliberations at World TB Day events globally provide another opportunity for donors and countries to reflect on and take action to deliver their commitments to a tuberculosis free world.

We are all members of the STOP TB Partnership. AZ is a co-principal investigator of the PanAfrican Network on Emerging and Re-Emerging Infections (PANDORA-ID-NET) funded by the European and Developing Countries Clinical Trials Partnership, EU Horizon 2020 Framework Programme for Research and Innovation. ZA is in receipt of a UK National Institutes of Health Research senior investigator award. We declare no other competing interests.

Suvanand Sahu, Lucica Ditiu, Lovett Lawson, Francine Ntoumi, Denise Arakaki, *Alimuddin Zumla

\section{a.zumla@ucl.ac.uk}

Stop TB Partnership Secretariat, Global Health Campus, Geneva, Switzerland (SS, LD); Zankli Medical Services, Abuja, Nigeria (LL); Marien NGouabi University, Brazzaville, Congo (FN); Institute for Tropical Medicine, University of Tübingen, Tübingen, Germany (FN); Ministério da Saúde, Secretaria de Vigilância em Saúde, Brasília, Brasil (DA); Ministry of Health, National 
Tuberculosis Control Program, Brasilia, Brazil (DA); Division of Infection and Immunity, Center for Clinical Microbiology, University College London, London, UK (AZ); and National Institute of Health Research Biomedical Research Centre, University College London Hospitals NHS Foundation Trust, London, UK (AZ)

1 United Nations General Assembly Resolution A/RES/73/3. Political declaration of the highlevel meeting of the General Assembly on the fight against tuberculosis. October, 2018. https://www.un.org/en/ga/search/view_doc.asp?symbol=A/RES/73/3 (accessed March 6, 2020).

2 Sahu S, Ditiu L, Zumla A. After the UNGA High-Level Meeting on Tuberculosis-what next and how? Lancet Glob Health 2019; 7: e558-60.

3 Nadda JP. India's leadership to end tuberculosis. Lancet 2019; 393:1270-72.

4 Stop TB Partnership and TB-People. Declaration of the rights of people affected by TB. 2019.

http://stoptb.org/assets/documents/communities/Declaration\%20of\%20the\%20rights\%2 0of\%20people\%20affected\%20by\%20TB\%20-\%20A5\%20english\%20version.pdf (accessed March 6, 2020).

5 WHO. Global tuberculosis report 2019. 2019.

https://www.who.int/tb/publications/global_report/en/ (accessed March 6, 2020).

6 WHO. Rapid communication: molecular assays as initial tests for the diagnosis of tuberculosis and rifampicin resistance. January, 2020. https://apps.who.int/iris/bitstream/handle/10665/330395/9789240000339-eng.pdf (accessed March 6, 2020).

7 WHO. Rapid communication: key changes to the treatment of drug-resistant tuberculosis. December, 2019.

https://www.who.int/tb/publications/2019/WHO_RapidCommunicationMDR_TB2019.pdf ?ua=1 (accessed March 6, 2020).

8 The Stop TB Partnership. Global Drug Facility: Pediatric Drug-Resistant TB initiative http://www.stoptb.org/news/stories/2019/ns19 035.html (accessed March 6, 2020).

9 Stop TB Partnership. Stop TB Partnership Board Call for dramatic increases in funding for TB. 2019. http://www.stoptb.org/news/stories/2019/ns19_005.asp (accessed March 6, 2020). 
10 Stop TB Partnership 2019. Global plan to end TB 2018-2022: reaching the UN TB targets.

http://www.stoptb.org/global/plan/plan1822.asp (accessed March 6, 2020).

11 Reid MJA, Arinaminpathy N, Bloom A, et al. Building a tuberculosis-free world: The Lancet Commission on tuberculosis. Lancet 2019; 393: 1331-84.

12 The Lancet. End the tuberculosis emergency: a promise is not enough. Lancet, 2019; 394: 1482.

Figure: Progress against UNGA Political Declaration on Tuberculosis (TB) global cumulative targets for 2018-22

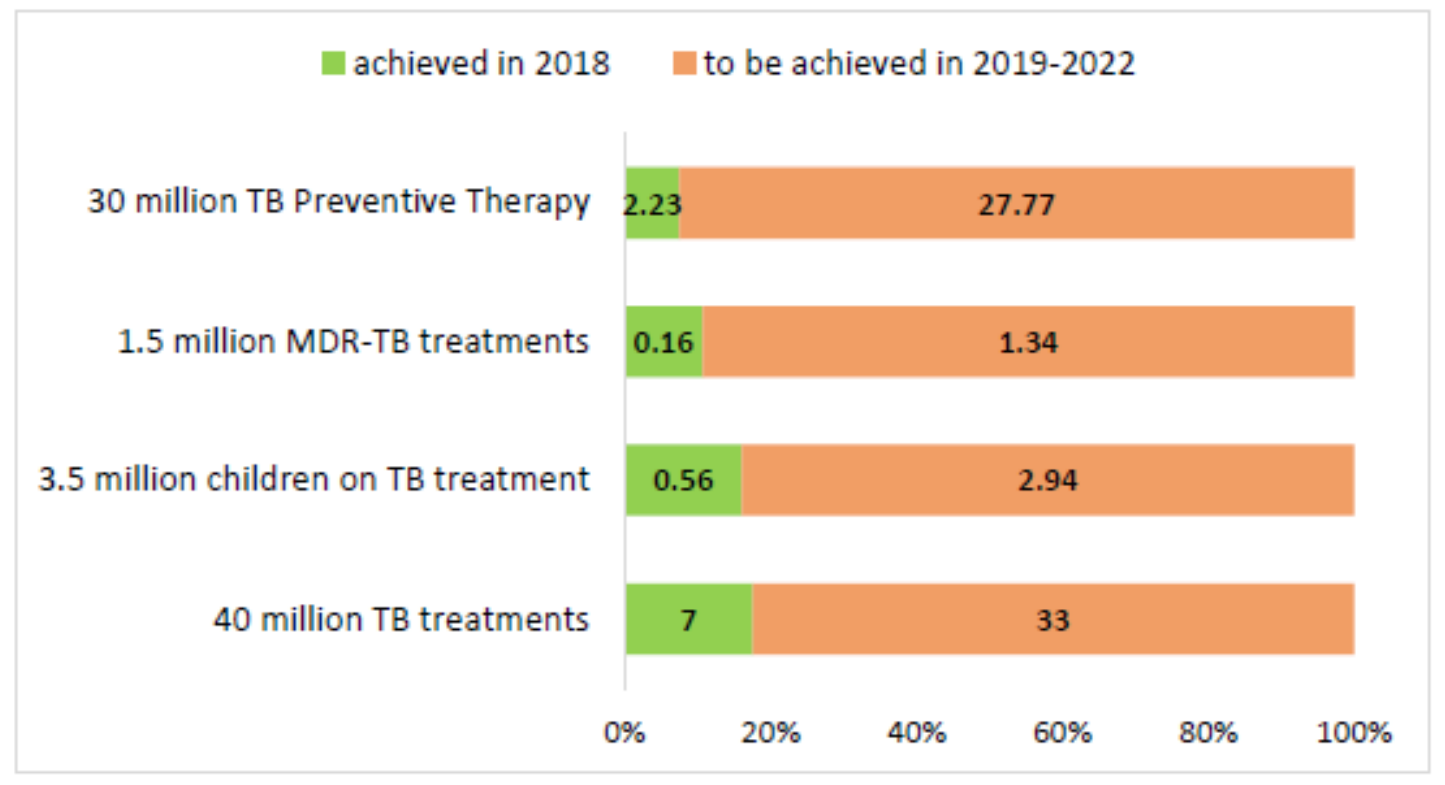

